\title{
Aging Precipitation Behavior and Mechanical Properties of Inconel 617 Superalloy
}

\author{
Yan GUO ${ }^{\dagger}$, Bohan WANG and Shufang HOU \\ Materials Department, Xi'an Thermal Power Research Institute Co., Ltd., Xi'an 710032, China \\ [Manuscript received 10 December 2012, in revised form 26 March 2013] \\ (c) The Chinese Society for Metals and Springer-Verlag Berlin Heidelberg
}

\begin{abstract}
Aging precipitation behavior and mechanical properties of Inconel 617 superalloy aged at $760{ }^{\circ} \mathrm{C}$ for up to $10000 \mathrm{~h}$ were investigated. The results showed that the precipitates of the aged alloy are $M_{23} \mathrm{C}_{6}$ and $M_{6} \mathrm{C}$ carbides and $\gamma^{\prime}$ phase. The carbide particles precipitated both at the grain boundaries and within grains, and the $\gamma^{\prime}$ phase particles were situated at intragranular sites in the process of aging. The carbide particles were discontinuously dispersed at grain boundaries after aging for $3000 \mathrm{~h}$, while after aged for $5000 \mathrm{~h}$ the carbide particles are merged. The precipitates inside grains remained stable even after aging for $10000 \mathrm{~h}$. The hardness was increased for the alloy aged for $300 \mathrm{~h}$ up to $3000 \mathrm{~h}$, which was resulted primarily from the precipitation of carbides as discrete particles both at the grain boundaries and inside grains. Small quantity $\gamma^{\prime}$ precipitates were formed inside grains, to some extent, which contributed to an enhanced hardness. However, a decrease of the hardness was observed after aging for $5000 \mathrm{~h}$. A significant drop in toughness of the alloy aged for $300 \mathrm{~h}$ was attributed to the reduction of the bonding interface strength when carbides precipitated at grain boundaries. Thereafter, the toughness decreased slowly with the prolonged aging time. The high temperature tensile properties of the aged alloy are rather stable even aged for 300-3000 h.
\end{abstract}

KEY WORDS: Inconel 617; Superalloy; Aging; Precipitate; Mechanical properties

\section{Introduction}

In recent years, the efficient Ultra Supercritical (USC) units operate at steam temperatures of approximately $600{ }^{\circ} \mathrm{C}$ with steam pressures of 25 $30 \mathrm{MPa}$. Some ferric and austenitic stainless steels are widely used for such units, e.g. P92, TP347HFG and TP310HNbN. Currently, there is a strong incentive to increase the working temperature and steam pressure in coal-fired power plants in order to improve plant efficiency and reduce emissions. Target steam conditions are $700{ }^{\circ} \mathrm{C}$ or higher and $35 \mathrm{MPa}$ for plants that are designed for Advanced Ultra Supercritical (A-USC), significantly higher than those of the conventional plants.

As for the working condition for A-USC, 9\%-

\footnotetext{
† Corresponding author. Assoc. Prof., Ph.D.; Tel: +86 29 82102410-2; Fax: +86 29 83255651; E-mail address: guoyan9732@gmail.com (Yan GUO)
}

DOI: $10.1007 / \mathrm{s} 40195-012-0249-3$
$12 \% \mathrm{Cr}$ steels and other materials could not commonly be used in coal-fired plants. Thus, collaborative projects to investigate alternative materials have been conducted in Europe, Japan and the United States $^{[1-3]}$. Several nickel-base alloys have emerged as principal candidates for A-USC application due to their excellent high-temperature strength, good resistance to creep, better anti-oxidation ability, and high hot corrosion resistance such as alloy 617 and its modified versions, alloy 740 and so on ${ }^{[4-7]}$. Alloy 617 belongs to the group of nickel-base alloys usually referred to as solid-solution strengthened materials ${ }^{[8,9]}$. The relationship between microstructure and creep properties of alloy 617 have been reported in Ref. [1012]. The effect of microstructure on the hardness was investigated by $\mathrm{Wu}$ et al. ${ }^{[13]}$. The properties of this alloy are strongly influenced by microstructural features in the process of aging. Thus, this paper focuses on the aging precipitation behavior of this alloy and its effect on certain mechanical properties such as hardness, tensile properties and toughness, which are 
Table 1 Chemical composition of Inconel 617 superalloy (wt.\%)

\begin{tabular}{cccccccccccccc}
\hline $\mathrm{C}$ & $\mathrm{Si}$ & $\mathrm{Mn}$ & $\mathrm{S}$ & $\mathrm{Al}$ & $\mathrm{B}$ & $\mathrm{Co}$ & $\mathrm{Cr}$ & $\mathrm{Cu}$ & $\mathrm{Fe}$ & $\mathrm{Mo}$ & $\mathrm{Ti}$ & $\mathrm{P}$ & $\mathrm{Ni}$ \\
\hline 0.06 & 0.11 & 0.06 & 0.001 & 0.95 & 0.001 & 12.0 & 21.5 & 0.06 & 1.24 & 9.23 & 0.35 & 0.005 & Bal. \\
\hline
\end{tabular}

of vital importance to application for large diameter heavy-wall pipe.

\section{Experimental}

The chemical composition of Inconel 617 alloy (batch number HRH1627/01) used in this study is presented in Table 1.

The as-received alloys were solution treated at $1149{ }^{\circ} \mathrm{C}$ for $30 \mathrm{~min}$ and water quenched. They were then aged at $760{ }^{\circ} \mathrm{C}$ for $300,1000,3000,5000$ and $10000 \mathrm{~h}$, respectively. The hardness of the tested samples was measured with a HB-3000C Brinell hardness tester. The $55 \mathrm{~mm} \times 10 \mathrm{~mm} \times 7.5 \mathrm{~mm} \mathrm{~V}$-notched Charpy impact samples were used to measure the impact toughness at room temperature on a PKP450 impact testing machine. High temperature tensile test at $700{ }^{\circ} \mathrm{C}$ for the tested samples were performed on a Z150 tensile testing machine.

For as-received alloys, metallographic samples were ground to 1000-grit and mechanically polished, and then etched using a solution of $\mathrm{HCl}, \mathrm{HNO}_{3}$ and $\mathrm{H}_{2} \mathrm{O}$. For the aged alloys, metallographic samples were ground to 1500-grit and electro-polished with a solution of $\mathrm{H}_{2} \mathrm{SO}_{4}$ and $\mathrm{CH}_{3} \mathrm{OH}$, then electroetched with a solution of $\mathrm{H}_{2} \mathrm{SO}_{4}$ and $\mathrm{H}_{2} \mathrm{O}$. Metallographic inspections were carried out using a FEI Quanta-400HV scanning electron microscope (SEM). Energy dispersive spectroscopy (EDS) micro-analysis was performed in SEM. Fracture surfaces of impact samples were also analyzed by SEM.

Samples used for transmission electron microscopy (TEM) analysis were prepared as follows. A foil of about $500 \mu \mathrm{m}$ thick was cut and mechanically ground to a thickness of $40 \mu \mathrm{m}$, from which TEM disks of $3 \mathrm{~mm}$ in diameter were punched. Twin-jet electropolishing was performed using a $10 \%$ perchloric acid $+90 \%$ acetic acid solution at room temperature, with a polishing current of $30 \mathrm{~mA}$. TEM observation was carried out in a JEM-3010 high-resolution transmission electron microscopy (HR-TEM) operating at $300 \mathrm{kV}$. The phase identification was performed using the selected area electron diffraction (SAED) pattern.

\section{Results and Discussion}

Fig. 1 reveals the SEM microstructural evolution with aging time. The secondary phases observed in the SEM images were of two types as showed in Fig. 1(a). The first type of particles distributed nearby grain boundaries with diameters of $\sim 6 \mu \mathrm{m}$ were rich in $\mathrm{Ti}$ and $\mathrm{N}$, and were therefore probably TiN. The other sort of particles with diameters of $0.6-3.0 \mu \mathrm{m}$ irregularly dispersed within the matrix contained elements of Cr, Mo and Fe, and were probably ( $\mathrm{Cr}, \mathrm{Mo}$, $\mathrm{Fe})_{23} \mathrm{C}_{6}$ carbides $^{[10]}$. Backscattered electron (BSE) image revealed that the high temperature aging led to the precipitation of a large number of particles both within grains and at grain boundaries. However, the size, morphology and distribution of carbides changed clearly with prolonged aging time. For instance, the discontinuously precipitated carbides were observed at grain boundaries of the alloys aged for $3000 \mathrm{~h}$ (Fig. 1(b)). After aging for $5000 \mathrm{~h}$, the carbides along grain boundaries began to aggregate and distribute continuously and the quantity of $M_{6} \mathrm{C}$ particles (bright) increased significantly. EDS result shows that $M_{6} \mathrm{C}$ is rich in Mo (not shown here).

Fig. 2 shows the TEM morphologies of the precipitates inside grains of the alloys aged for different times. As shown in Fig. 2(a), spherical particles indexed as $\gamma^{\prime}$ phase were $\sim 35 \mathrm{~nm}$ in diameter and particles attributed to $M_{23} \mathrm{C}_{6}$ carbides were $\sim 140 \mathrm{~nm}$ in length. Fig. 2(b) depicted polyhedral particles with a length of $70-120 \mathrm{~nm}$ indexed as $M_{23} \mathrm{C}_{6}$ carbides. At the same time, it is clear that a small fraction of $\gamma /-\mathrm{Ni}_{3}(\mathrm{Al}, \mathrm{Ti})$ particles with a diameter of about 20 $40 \mathrm{~nm}$ for the alloy aged for $5000 \mathrm{~h}$. As for the alloy aged for $10000 \mathrm{~h}$, a small number of $\gamma^{\prime}$ phase with the size of 30-35 nm and $M_{23} \mathrm{C}_{6}$ particles of 70-140 nm were observed (Fig. 2(c)). As shown in Fig. 2, the volume fraction of carbides has no much change and size of carbide particles remains almost the same during aging. The aged alloy contains a large fraction of carbide particles. TEM morphology of $\gamma^{\prime}$ phase in the aged alloy has no remarkable change in shape in the process of aging. The spherical $\gamma^{\prime}$ precipitates indicated strong coherency between $\gamma^{\prime}$ and the matrix and a low degree of mismatch between the lattice parameters of both phases. SAED pattern revealed that $\gamma^{\prime}$ phase possessed ordered face-centered-cubic (fcc) structure with lattice parameter of $\sim 0.353 \mathrm{~nm}^{[7]}$. The particle size of $\gamma^{\prime}$ phase kept unchanged during aging. These ultra-fine $\gamma^{\prime}$ precipitates were distributed in the grains, which contributes the strengthening effect for the alloy.

Fig. 3 reveals the TEM morphologies of the precipitates at gain boundaries of the alloys aged for different times. $M_{23} \mathrm{C}_{6}$ particles with a length of 500 $1000 \mathrm{~nm}$ were observed discontinuously along grain boundaries as shown in Fig. 3(a). Polyhedral $M_{23} \mathrm{C}_{6}$ particles nearby and at grain boundaries was also visible in Fig. 3(b). Fig. 3(c) and Fig. 3(d) illustrated $M_{23} \mathrm{C}_{6}$ and $M_{6} \mathrm{C}$ carbide particles continuously along grain boundaries.

The hardness of the as-received alloy and aged 


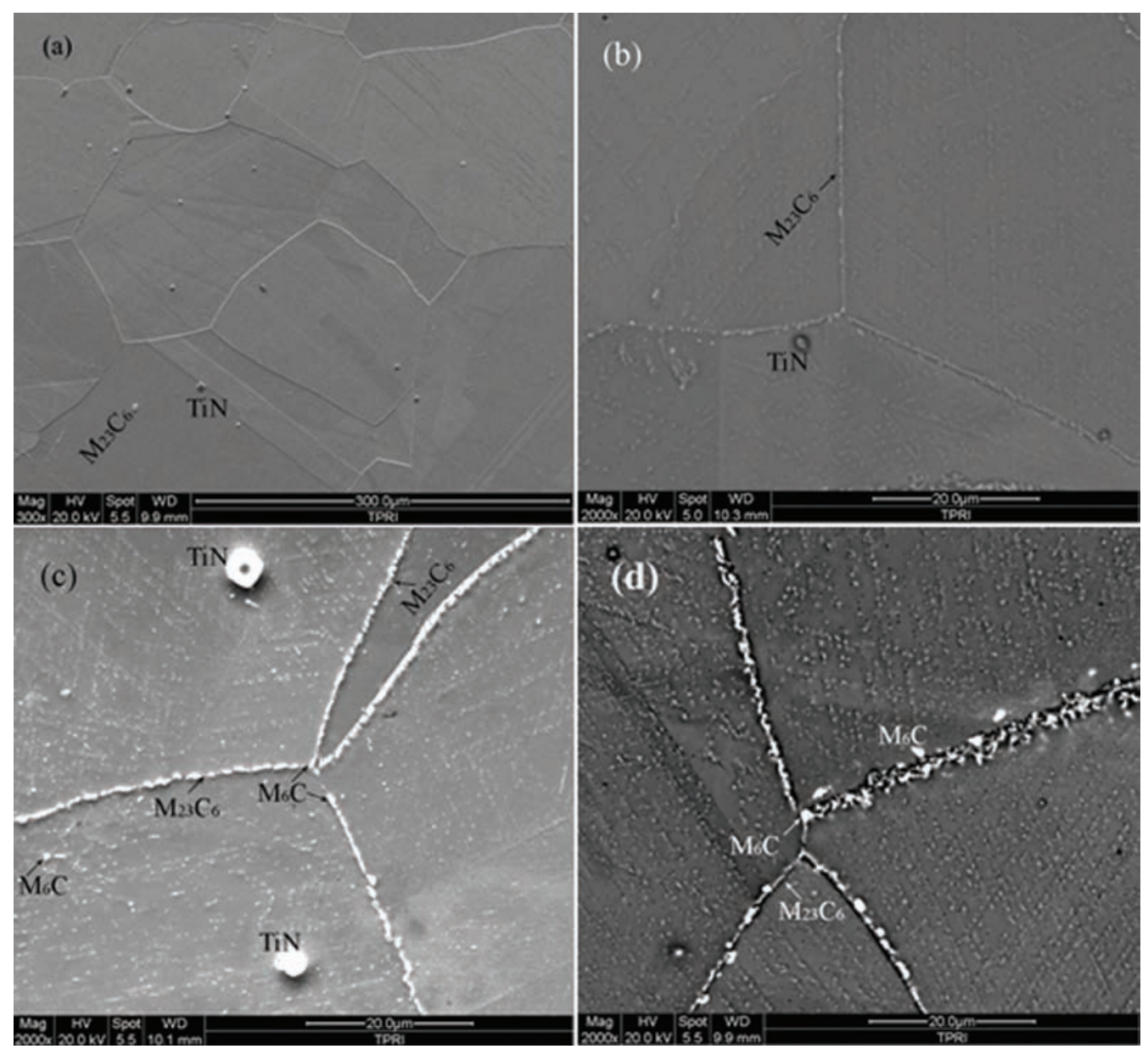

Fig. 1 SEM images of the alloys aged for different time: (a) 0 h, SE; (b) 3000 h, BSE; (c) 5000 h, BSE; (d) 10000 h, BSE
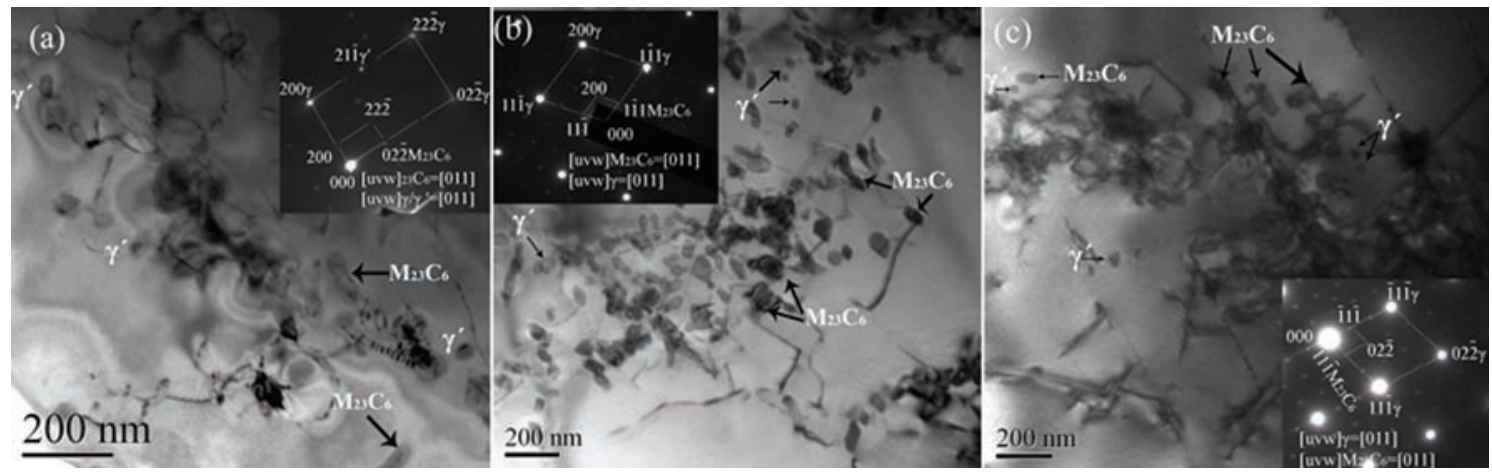

Fig. 2 TEM photographs showing the precipitates within the grains of the alloy aged for different time: (a) $3000 \mathrm{~h}$; (b) $5000 \mathrm{~h} ;$ (c) $10000 \mathrm{~h}$

samples at room temperature is presented in Fig. 4. The alloy had a low hardness value in the as-received condition. A remarkable increase in hardness was observed during the first period of the aging (between 0 and $300 \mathrm{~h}$ ). After that, the hardness changed slightly for the aged alloys in the period of 300-3000 h, which was in close relation with precipitation hardening mechanism observed both inside grains and at grain boundaries. A small amount of fine $\gamma^{\prime}$ particles dispersed inside grains does provide some hardening for the aged alloys. The hardening of the aged alloy is found to result primarily from the precipitation of carbides as discrete particles at grain boundaries and inside grains. As far as the intragranular carbides are concerned, the particles insides grains remain small and discrete because of the relatively slow diffusion rate of large elements in the precipitates and in the matrix. The intragranular carbides contributed to the 

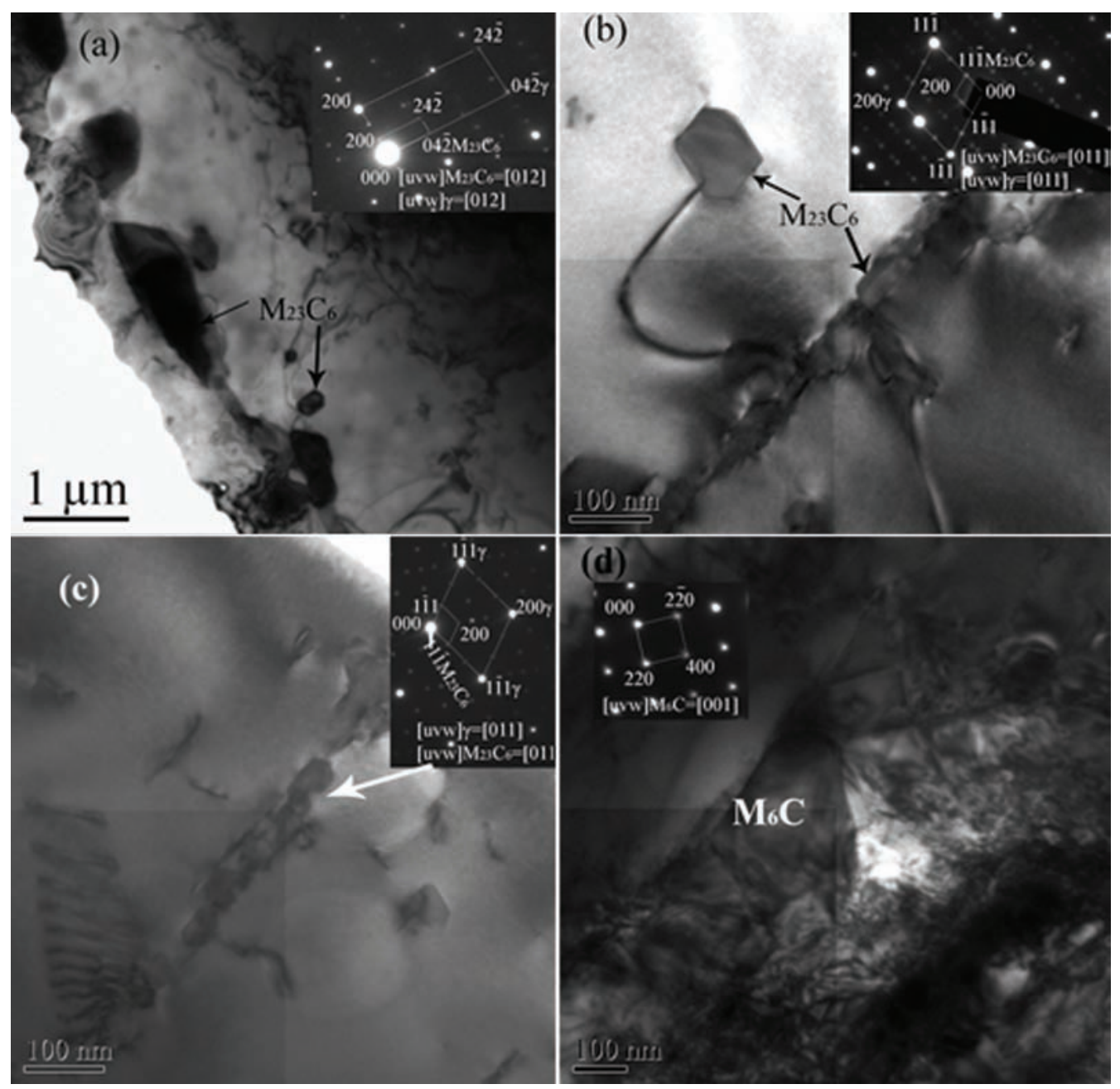

Fig. 3 TEM photographs showing the intergranular precipitates of the alloy aged for different time: (a) 3000 h; (b) $5000 \mathrm{~h} ;(\mathrm{c}, \mathrm{d}) 10000 \mathrm{~h}$

strengthening effect by acting as barriers for dislocation motion and by stabilizing dislocations. The discrete nature of the grain boundary carbides enhances hardness because it causes pinning of the boundary and decreases grain boundary sliding. However, with an increase of the aging time from 3000 to $5000 \mathrm{~h}$, a decrease in hardness from $223 \mathrm{HB}$ to $200 \mathrm{HB}$ was observed. It is likely that a significant increase of $M_{6} \mathrm{C}$ particles led to a decrease of Mo solution strengthening. In the period of 5000-10000 h, the hardness remained almost unchanged for the aged alloys. At the same time, Fig. 4 reveals the effect of aging time on the impact absorbed energy of the alloys, which is the characterization for the toughness. The as-received alloy exhibited the highest toughness and the drop in toughness occurred predominately during the first aging period. After aging for more than $300 \mathrm{~h}$, the toughness values decreased slowly with increasing aging time. A continuous decrease of these values with increasing aging time demonstrated that the alloy experienced a ductile to brittle transition. A similar phenomenon occurs in $25 \mathrm{Cr}-20 \mathrm{Ni}-\mathrm{Nb}-\mathrm{N}$ steel ${ }^{[14]}$.

Fig. 5 shows the SEM photographs of the frac-

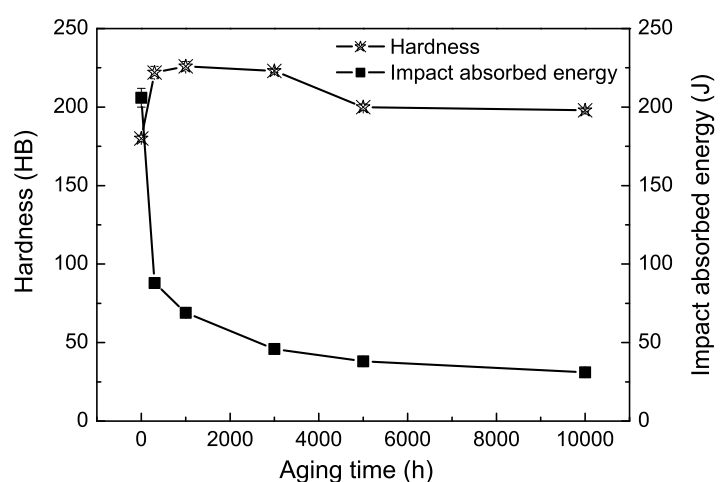

Fig. 4 Changes of hardness and impact absorbed energy of the alloys with aging time

tured surfaces after impact test of the alloys under four different conditions. In the case of the as-received alloy, the fracture surface was predominantly of ductile nature revealed by the occurrence of large dimples. After aging for $300 \mathrm{~h}$ or more, the fracture mode changed from ductile to brittle. This is believed to be the result of the carbides formed at grain bound- 

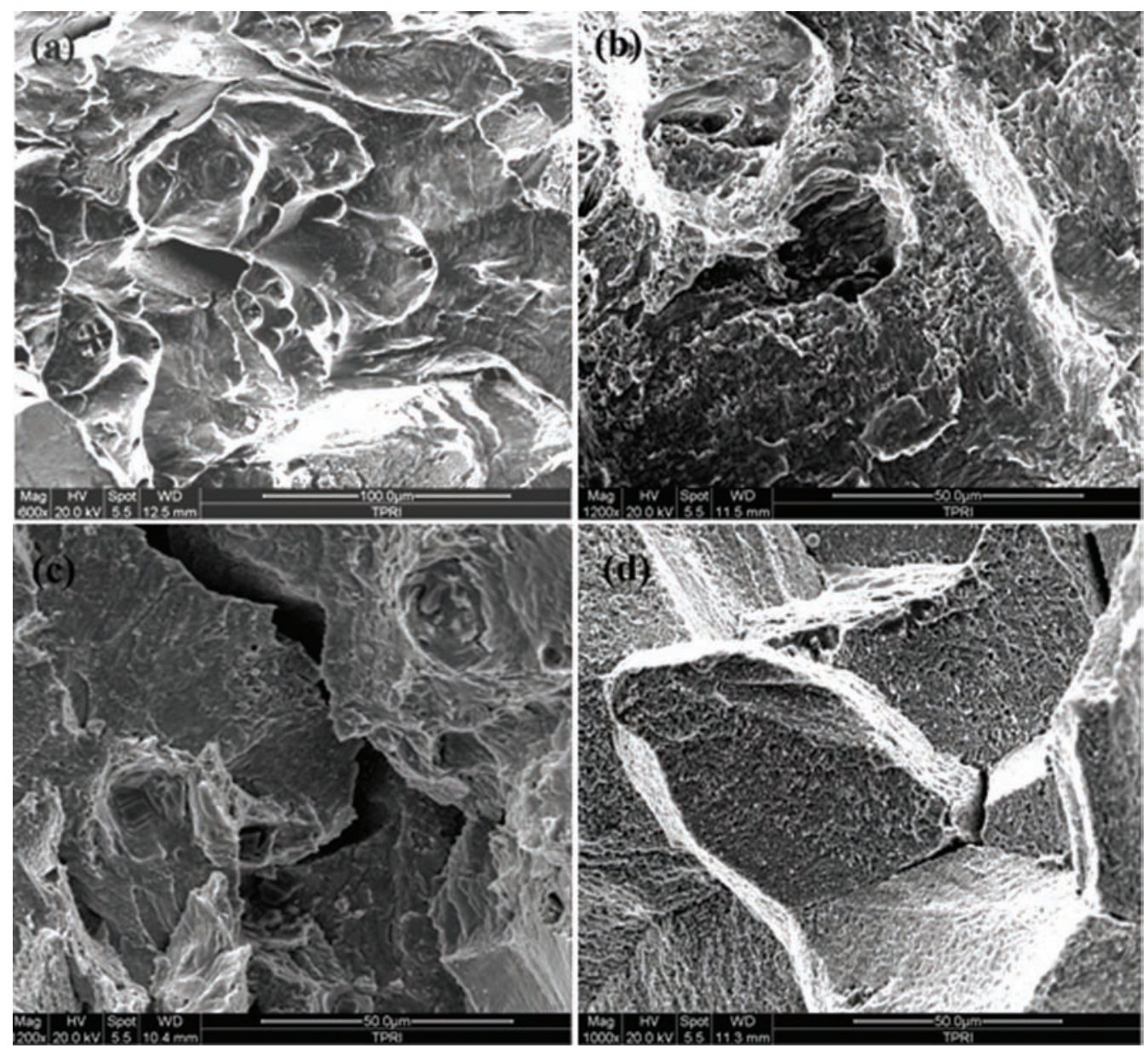

Fig. 5 The fractured surfaces after impact test for superalloy Inconel 617: (a) as-received; (b) aged for 300 h; (c) aged for $1000 \mathrm{~h}$; (d) aged for $10000 \mathrm{~h}$

aries after aging. The grain boundaries are weakened by grain boundary carbides and the separation occurs by decohesion of carbide/matrix interface. At the same time, the interfaces between carbides and the matrix become initiation sites for fracture. Hence, cracks may mainly take place at grain boundaries during the impact test. The separated surfaces appear smooth due to the distribution of the grain boundary carbides. These inter-granular cracks apparently lead to a decrease in toughness for the aged alloys. Increasing aging time from 300 to $10000 \mathrm{~h}$ resulted in a decrease in the number and size of dimples.

The tensile properties of the tested alloy at elevated temperature of $700{ }^{\circ} \mathrm{C}$ are presented in Fig. 6 and Fig. 7. The as-received alloy exhibited the low values of ultimate tensile strength (UTS) and yield strength (YS). The maximum values of strengths were achieved for the alloy aged for $1000 \mathrm{~h}$. When the aging time is further increased to $3000 \mathrm{~h}$, the strength is slightly decreased. It is clear that the strength of the aged alloy remained almost unchanged in the process of aging as shown in Fig. 6. The as-received alloy showed the highest ductility, which is inferred from the highest values of total elongation and area reduc-

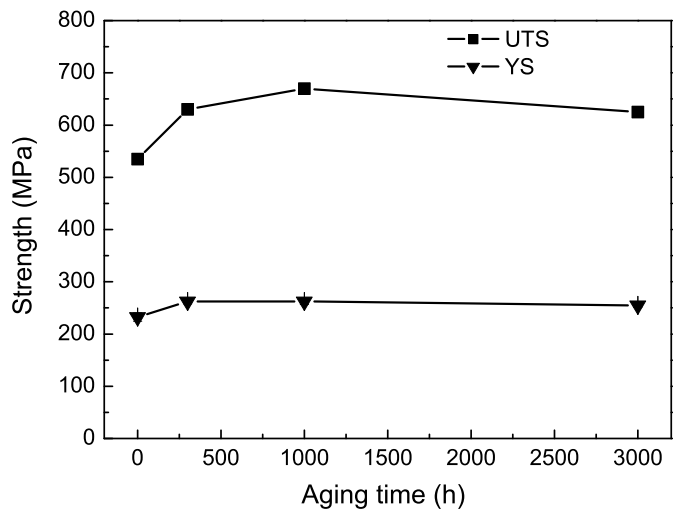

Fig. 6 Variation of the high temperature $\left(700{ }^{\circ} \mathrm{C}\right)$ strengths of Inconel 617 superalloy with aging time

tion. A drop in ductility was observed after aging for $300 \mathrm{~h}$; however, the ductility of the aged alloy still maintained a higher level and kept almost unchanged in the period of 300-3000 h. Fig. 6 and Fig. 7 indicate that this alloy possesses good and stable tensile properties at elevated temperature. 


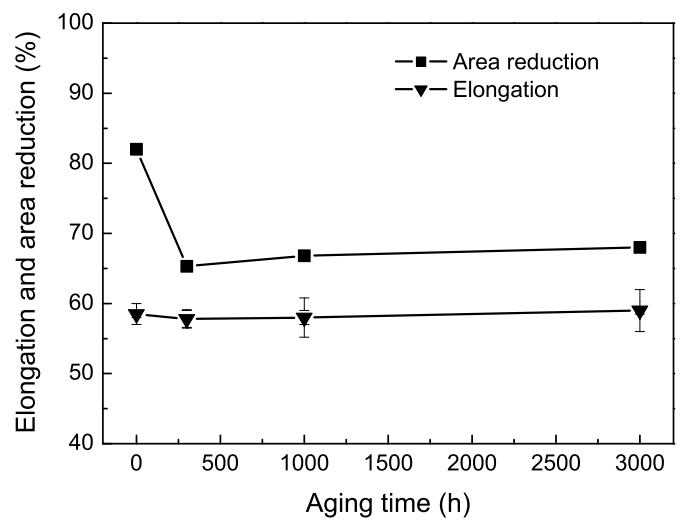

Fig. 7 Variation of the high temperature $\left(700{ }^{\circ} \mathrm{C}\right)$ ductility of Inconel 617 superalloy with aging time

\section{Conclusions}

(1) For Inconel 617 superalloy aged for $10000 \mathrm{~h}$, the particle sizes of carbide and $\gamma^{\prime}$ phase remain unchanged within the grains. There are dispersed carbides at the grain boundaries for this alloy aged for $3000 \mathrm{~h}$, while after $5000 \mathrm{~h}$ aging continuous precipitation of carbide particles occurred at grain boundaries.

(2) Hardness is significantly increased for the aged alloys as compared with as-received alloy, which is due to a combined effect of intragranular and grain boundary hardening. The bonding strength of the grain boundaries is weakened by carbides precipitation at the grain boundaries, which gives rise to the reduction in toughness and occurrence of intergranular fracture.

(3) The Inconel 617 super alloy aged for 300$3000 \mathrm{~h}$ has a good and stable tensile strength at elevated temperature.

\section{Acknowledgements}

This work was supported by the CSEE Youth Science
\& Technology Innovation Project (No.003) and National Energy Applied Technology Research \& Demonstration Project (No.NY20110102-1).

\section{REFERENCES}

[1] C. DavidTung and C. John Lippold, Proc of the 12th International Symposium on Superalloys, Seven Springs, PA, US, Sept. 9-13, 2012.

[2] J. Bratberg, H. Mao, L. Kjellqvist, A. Engström, P. Mason and Q. Chen, Proc of the 12th International Symposium on Superalloys, Seven Springs, PA, US, Sept. 9-13, 2012.

[3] J. Sato, H. Kamoshida and S. Imano, Proc of the 3rd Symposium on Heat Resistant Steels and Alloys for High Efficiency USC Power Plants, Tsukuba, Japan, June 1-4, 2009.

[4] Y. Yamamoto , M. Takeyama, Z.P. Lu, N.D. Evans, P.J. Maziasz and M.P. Brady, Intermetallics 16 (2008) 453.

[5] S.K. Mannan and S.J. Patel, Mater. Sci. Forum. $\mathbf{5 4 6}$ - 549 (2007) 1271.

[6] N.D. Evans, P. J. Maziasz, R.W. Swindeman and G.D. Smith, Scr. Mater. 51 (2004) 503.

[7] S.Q. Zhao, Y. Jiang, J.X. Dong and X.S. Xie, Acta Metall. Sin. (Engl. Lett.) 19(2006) 425.

[8] S. Rahman, G. Priyadarshan, K.S. Raja, C. Nesbitt and M. Misra, Mater. Lett. 62 (2008) 2263.

[9] J. Roster, M. Gotting, D. Del Genovese, B. Böttger, R. Kopp, M. Wolske, F. Schubert, H.J. Penkalla, T. Seliga, A. Thoma, A. Scholz and C. Berger, Adv. Eng. Mater. 5 (2003) 469.

[10] M. Cabibbo, E. Gariboldi, S. Spigarelli and D. Ripamonti, J. Mater. Sci. 43 (2008) 2912.

[11] S. Schlegel, S. Hopkins, E. Young, J. Cole, T. Lillo and M. Frary, Metall. Mater. Trans. A 40 (2009) 2812.

[12] E. Gariboldi, M. Cabibbo, S. Spigarelli and D. Ripamonti, Int. J. Press. Vessel Pipe. 85 (2008) 63.

[13] Q. Wu, H. Song, W. Robert, J. P. Shingledecker and V.K. Vasudevan, Metall. Mater. Trans. A 39 (2008) 2569.

[14] B. Peng, H. Zhang, J. Hong, Q. Wang and H. Zhang, Mater. Sci. Eng. A 527 (2010)1957. 